\title{
Review Article \\ Traditional Birth Attendants and Policy Ambivalence in Zimbabwe
}

\author{
Naume Zorodzai Choguya \\ Sociology Department, University of Zimbabwe, P.O. Box MP 167, Mount Pleasant, Harare, Zimbabwe \\ Correspondence should be addressed to Naume Zorodzai Choguya; zchoguya@gmail.com
}

Received 20 September 2013; Revised 23 December 2013; Accepted 24 December 2013; Published 7 May 2014

Academic Editor: Kaushik Bose

Copyright (C) 2014 Naume Zorodzai Choguya. This is an open access article distributed under the Creative Commons Attribution License, which permits unrestricted use, distribution, and reproduction in any medium, provided the original work is properly cited.

\begin{abstract}
This paper analyses the importance of the services rendered by traditional birth attendants (TBAs) to pregnant women in Zimbabwe. It argues that, though an integral part of the health system, the ambivalence in terms of policy on the part of the government leaves them in a predicament. Sociocultural values as well as tradition imbue TBAs power and authority to manage pregnancies and assist in child deliveries. On the other hand, government policies expounded through the Ministry of Health (MoH) programs and policies appear to be relegating them to the fringes of healthcare provision. However, in a country with a failing health system characterized by mass exodus of qualified personnel, availability of drugs, and understaffing of healthcare centres, among others, TBAs remain the lifeline for many women in the country. Instead of sidelining them in healthcare interventions, I argue that their integration, however, problematic and often noted to be with disastrous consequences for traditional medicine, presents the sole viable solution towards achieving MDGs 4 and 5. The government and $\mathrm{MoH}$ should capitalize on the availability of and standing working relations of TBAs with the grassroots for better/positive maternal health outcomes. In a country reeling with high maternal deaths, TBAs' status and position in society make them the best intervention tools.
\end{abstract}

\section{Introduction}

African traditional healthcare is grounded in thousands of years of knowledge and has sustained life, on its own or in concert with Western medicine. A traditional birth attendant is defined as a person who assists the mother during childbirth and initially acquired her skills by delivering babies herself or through apprenticeship to other TBAs [1]. According to Kruske and Barclay [2] approximately half of all births in developing countries are attended by traditional birth attendants (TBAs) and as many as $95 \%$ of women are attended by TBAs. It is against this background that I argue that rather than continuing to develop interventions grounded in a Western medicine world view of healthcare there is need to develop programs that are inclusive of healers who reflect the sociocultural beliefs of the community. There is also need to understand the local context and value traditional knowledge systems. Such calls are themselves not a new phenomenon; for example, Jordan [3] called for the replacement of topdown, culturally inappropriate, biomedically oriented models with those of mutual accommodation. This is what Graham [4] calls the "partnership paradigm," that is, the mutual cooperation of biomedical and indigenous systems. However, it is at the interface between biomedical (Western) and indigenous systems that problems arise and also lie. The worldwide hegemony of Western biomedicine makes mutual accommodation an elusive goal.

Globally, TBAs assist in $60-80 \%$ of all deliveries and even more in the rural areas of developing countries. For many women living in the global south, antenatal care as well as institutional deliveries with skilled health workers remains a distant reality. Inclination towards home births supervised by TBAs is associated with cultural norms and religious beliefs as well as cost and accessibility of the services. Many countries, including Zimbabwe, often have a shortage of trained medical professionals and maternal health care is thus usually provided by TBAs [5-7]. TBAs speak the local language, have the trust of community members, provide psychosocial support at birth, and are thus an integral part of African medicine [8-11]. Though their number in developing 
countries is not known, conservative estimates suggest that there will be about 180 million nonskilled birth attendants in sub-Saharan Africa by 2015 [12].

\section{The Zimbabwean Context}

In sub-Saharan African countries many child bearing women are still being attended by TBAs and relatives at deliveries [12, 13]. The literature shows that births without skilled personnel and without access to life-saving drugs are the commonest practice for millions of mothers in the poorest countries where mortality rates and morbidity of the mothers are the highest $[12,14]$. Recent statistics indicate that across the world 287,000 women die in pregnancy and childbirth every year [14]. This is translated as one mother dying every 2 minutes, 800 each day. In Zimbabwe, ten women die every day of pregnancy-related complications [15]. Moreover, 7-10 million women and girls suffer severe or long lasting illnesses caused by pregnancy and childbirth complications [14]. The use of unskilled personnel (including TBAs) is argued to be among the reasons for the high maternal and infant mortality rate in sub-Saharan Africa. This has been influenced by a global policy shift from TBA-focused intervention to skilled attendance and institutional birthing. For more than three decades, the WHO and other agencies of the United Nations promoted training of TBAs as a global public-health strategy to reduce maternal mortality [16]. However, lack of evidence to demonstrate that trained TBAs can reduce maternal mortality led to controversy over their training in relation to safe motherhood, and a policy shift to skilled birth attendance was suggested [1].

Despite the expansion of interventions, including construction of more health facilities close to the community, increased use of antenatal clinic, and increased coverage of immunisation [18], the problem of TBA supervised births has persisted. This paper argues that rather than treating them as an anathema in maternal health care, embracing the roles of TBAs and working with them could produce positive maternal health outcomes.

Zimbabwe is a land locked country in Southern Africa which is made up of 10 administrative provinces; 8 of which are rural provinces. Most Zimbabweans live in rural areas [19] where availability, accessibility, and affordability are key issues impinging on health access. The country inherited the Rhodesian health care system at independence in 1980 which had divided health services along racial lines. The distribution of resources was highly skewed towards hospital service provision for the small white population at the expense of the indigenous population. Postindependent Zimbabwe saw government expression of intent to redress the existing inequalities by investing especially in health services in rural areas. Health was viewed as an integral part of development and as a human right. These views guided the postindependence government's health policy, resource allocation decisions, and human resource development. By 1989 the number of rural health centres and clinics had increased from 247 at independence to 1062 resulting in much better geographical accessibility of primary care services.
In the 1980s and early 1990s these health centres were adequately manned [20].

Zimbabwe's health system is dominated by the public sector, which provides an estimated $65 \%$ of health care services in the country. The mission sector plays a major role in rural areas courtesy of the colonial legacy while the private for profit sector is predominantly focused in urban areas. Some facilities are operated by municipalities and receive block grants from government. The Access to Health Care Services Study of 2007 found that most communities live within a $5 \mathrm{~km}$ radius from their nearest health facilities, whilst $23 \%$ live between 5 and $10 \mathrm{~km}$ and $17 \%$ are over $10 \mathrm{~km}$ from their nearest health centre [21]. Health care in Zimbabwe has been categorized as pluralistic due to the existence of both traditional and biomedical systems [11, 22].

Historically, the Ministry of Health and Child Welfare has focused on Primary Health Care, with a strong emphasis on community-based approaches, complemented by robust referral systems and facilities. The 1980s showed a general improvement in most of the major health indicators and service utilization, attributable to the expansion and improvements in the area of primary health care; however, signs of deterioration were evident in the 1990s. The trends were a reversal of the gains made in the previous decade; for example, infant mortality rate (IMR) increased from 77 and 53 per 1,000 live births in 1992 to 94 and 67 in 2009. The infant mortality rate had decreased by 50 percent between 1980 and 1990, from 100 per 1,000 live births to 50 per 1,000 live births UNICEF. Maternal mortality increased dramatically from 283 per 100,000 live births in 1994 to 390 per 100,000 births in 1990 to 578 in 1999 to 555 in 2005/6 and 790 in 2008. This sharp rise in maternal mortality is largely explained by the rapid spread of the HIV and AIDS epidemic. The Maternal and Perinatal Mortality Study of 2007 shows that the maternal mortality has increased further to 725 per 100,000 live births, with HIV-and AIDS-related deaths accounting for $25.5 \%$ of all maternal deaths.

Whilst over $90 \%$ of pregnant women reportedly attend formal health facilities for antenatal care [23], more than $30 \%$ of deliveries take place outside the formal system [24, 25]. Skilled attendance at delivery dropped from $73 \%$ in 1999 to $60 \%$ in 2009 . Maternity services, like other primary health care services, are meant to be rendered free of charge in all primary health-care facilities in the country. However, antenatal services are not fully utilised by pregnant women. A study conducted in Zimbabwe by Tsu [26] indicated that the majority of women reported to clinics during the third trimester of pregnancy, which resulted in negative birth outcomes. Mathole et al. [27] indicated that women in Zimbabwe felt that pregnancy had to be kept secret during its early stages (first three months which constitute uterus formation) for fear of witchcraft. The pregnancy is protected from evil spirits who maybe inflicted by jealous people and who would bewitch the pregnant mother to give birth to a malformed infant or to suffer a miscarriage. Beliefs of witchcraft are a contributing factor to the delay in first attendance of an antenatal clinic [27]. Though women are expected to attend an antenatal clinic in their eighth week of pregnancy, studies indicate that they only start visiting a clinic at 26-27 weeks 
Antenatal care visits/skilled attendance at birth trends in Zimbabwe

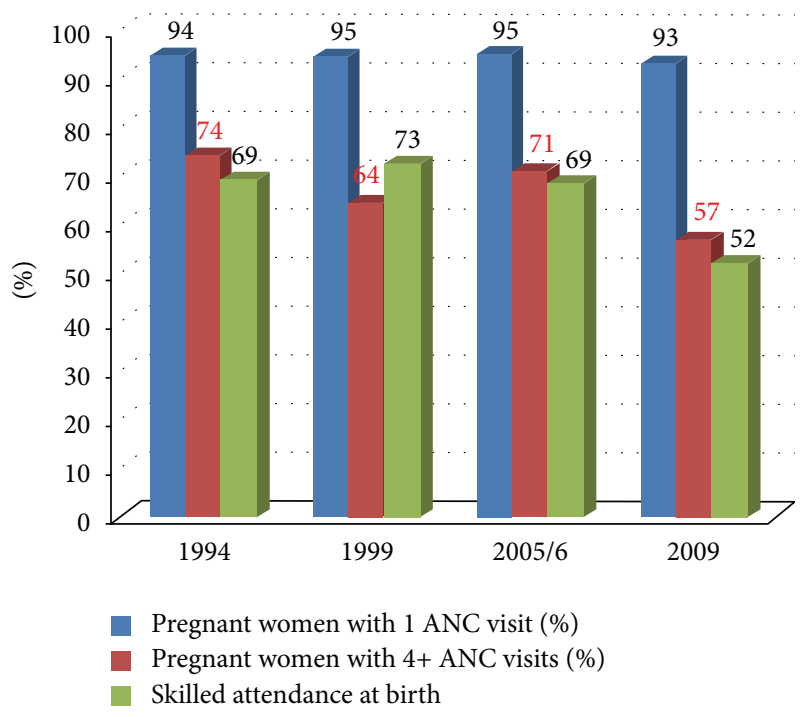

FIGURE 1: Source: Equinet Watch 2011 [17].

of gestation. This intentional delay of women to go for ANC often results in 1 ANC visit instead of the recommended 4. There has been an increase in women attending at least one antenatal care visit from $81 \%$ in 1999 to $94 \%$ in 2006 (ZDHS) and 93\% in 2009 (Multiple Indicator Monitoring SurveyMIMS). Institutional deliveries declined from $72 \%$ to $68 \%$ over the same period $[25,28]$, and subsequently to $61 \%$ in 2009 (MIMS). Therefore, despite attending at least one ANC visit it is clear that women then have their babies outside formal institutions often under the care of TBAs. It is against such a background that I argue for an enabling environment for TBAs to operate in. While women may not want to be seen attending the ANC clinics for fear of witchcraft, they are comfortable with consulting TBAs (Figure 1).

According to the WHO [1], the term "skilled attendant" refers to "an accredited health professional-such as midwife, doctor, or nurse-who has been educated and trained to proficiency in the skills needed to manage normal (uncomplicated) pregnancies, childbirth, and the immediate postnatal period, and in the identification, management, or referral of complications in women and newborns." Traditional birth attendants either trained or not are excluded from this category of skilled health workers. Thus, one can argue that these call for institutional birthing and or skilled attendance at birth have no regard for TBAs and their activities. If anything they marginalize, push to the fringes and drive to oblivion TBAs and their roles in maternal health care. In order to be effective, however, a skilled attendant requires an enabling environment that includes access to a referral system, communication and transport, drugs and supplies, and equipment. Furthermore, the enabling environmenta well functioning health system-requires adequate human resources and management systems, which ensure that there are sufficient skilled attendants with all the necessary skills deployed where they are needed; satisfactory pay scales

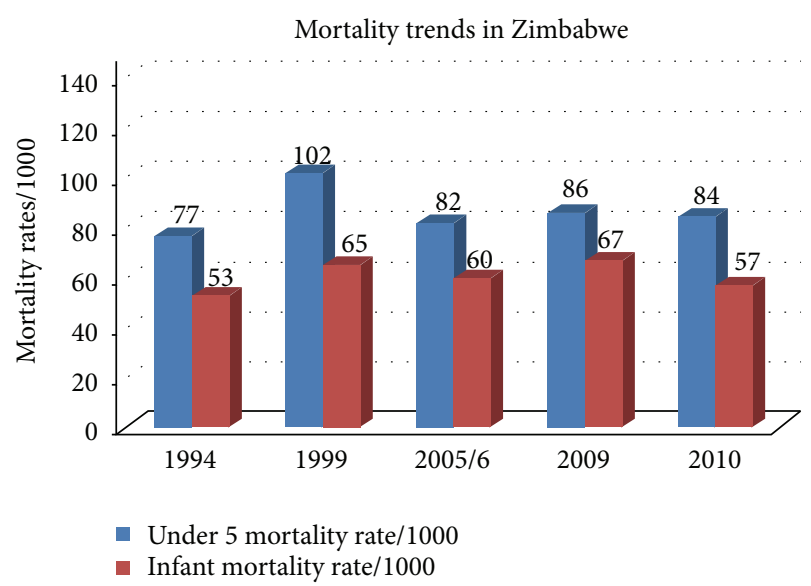

FIgURE 2: Source: Equinet Watch 2011 [17].

and career advancement opportunities, continuing education opportunities to maintain and upgrade skills; supportive supervision mechanisms, and possibilities for skilled attendants to refer women and newborns directly to higherlevel care if necessary [29]. The term skilled attendance therefore refers to both the skilled attendant and the enabling environment. In Zimbabwe, however, there are shortages of trained health personnel and the environment is not enabling either. Thus, calls for skilled attendance at birth and institutional birthing in the now are a far cry from reality.

There is limited information on coverage of neonatal interventions in Zimbabwe. The MOHCW is promoting Kangaroo Mother Care for preterm babies, expansion of comprehensive PMTCT, and promoting the Baby Friendly Hospital initiative. Neonatal care has now been incorporated in the Integrated Management of Childhood Illness (IMCI) guidelines; however, the implementation of this program has been a challenge. While the majority of essential interventions are home care practices which families can provide, there is lack of systematic implementation at community level. Some training of healthcare workers on Emergency Neonatal Care has been carried out but increasing coverage has been slow and inadequate. Attainment of key indicators that ensure the survival of neonates still needs to be improved.

The child mortality rate reflects the level and burden of poverty and is also a sensitive indicator of socioeconomic development. This general decline in mortality in the early years after independence can be attributed to massive investment in Primary Health Care (PHC) resulting in increased access to health care services throughout the country. This led to decline in maternal and child mortality. However, with the advent of economic structural adjustment programme and reforms there were removal of consumer subsidies and reduction in government spending. This reversed the social gains of the first decade after independence. This scenario was worsened by the emergence of the HIV/AIDS epidemic. Mortality in the country has been increasing since the early 1990s. This is true in all the other measures of mortality including infant, child, and maternal mortality (Figure 2). 
The under five mortality rate increased from 77 per 1000 live births in 1994 to 102 per 1000 live births in 1999 and then decreased to 97 per 1000 live births in 2009. The infant mortality (IMR) also followed a similar trend and as of 2009 was reported to be 67 per 1000 live births [25, 28, 30]. This rise in mortality between 1994 and 1999 was mainly attributed to the direct and indirect impact of the HIV and AIDS epidemic, declining coverage of immunisation against childhood illness, malnutrition, and the concomitant rise in poverty levels. The proportion of children 12-23 months fully immunized has dropped from $67 \%$ in 1997 to $49 \%$ in 2009 [30]. The Child Health Situation Analysis Study (2006) highlighted that the decline in child mortality rates could be linked to the overall decrease in HIV incidence and prevalence and greater access to opportunistic infection treatment for children. Additionally, in 1999 the government through the Ministry of Health and Child Welfare propounded The Integrated Management of Childhood Illnesses (IMCI) whose overall objective is to contribute towards the reduction of child morbidity and mortality. A number of programmes to improve the status of child health have been put in place in Zimbabwe. These include among others Vitamin A Supplementary programme, Expanded Programme of Immunisation (EPI), PMTCT Programme, and Village Health Worker programme. Evidently these programmes are embraced and designed within the confines of the formal health care system. They do not incorporate or leave room for TBAs. In a country where there is increased acceptance for TBAs and the services they offer any meaningful intervention ought to take them on board for positive health outcomes for the majority of the population.

Postindependent Zimbabwe has been embroiled in a protracted multifaceted crisis which has had detrimental effects for social service provision in the country particularly health and education sectors. The country's health system has been in decline characterized by the systematic decrease in coverage of most basic services and a rising maternal and child mortality rate. Rural-urban disparities in access to health care continue to grow. The increasing exodus of staff, high hospital fees, and shortage of essential drugs have forced many more people to seek traditional health care [31-33]. In Zimbabwe, the crisis in the formal health care system has forced hospital professionals, including medical doctors, to accept and even encourage people to use traditional care [33]; hence, the need to understand and work with TBAs as the alternative care providers.

Maternal mortality remains a cause for concern, as most maternal deaths are preventable through increased access to antenatal, delivery, and postnatal care. The 2005/06 Zimbabwe Demography and Health Survey showed that maternal mortality ratio has been increasing from 283 per 100,000 live births in 1994 to 578 and 555 per 100,000 live births in 1999 and 2005/6, respectively. The Maternal and Perinatal Mortality Study of 2007 shows that the maternal mortality has increased further to 725 per 100,000 live births. More recently the ZDHS [15] highlighted that maternal mortality has further increased to 925 per 100,000 live births (Figure 3). According to the 2004 Maternal and Neonatal Health Services Assessment maternal deaths were due to three delays:

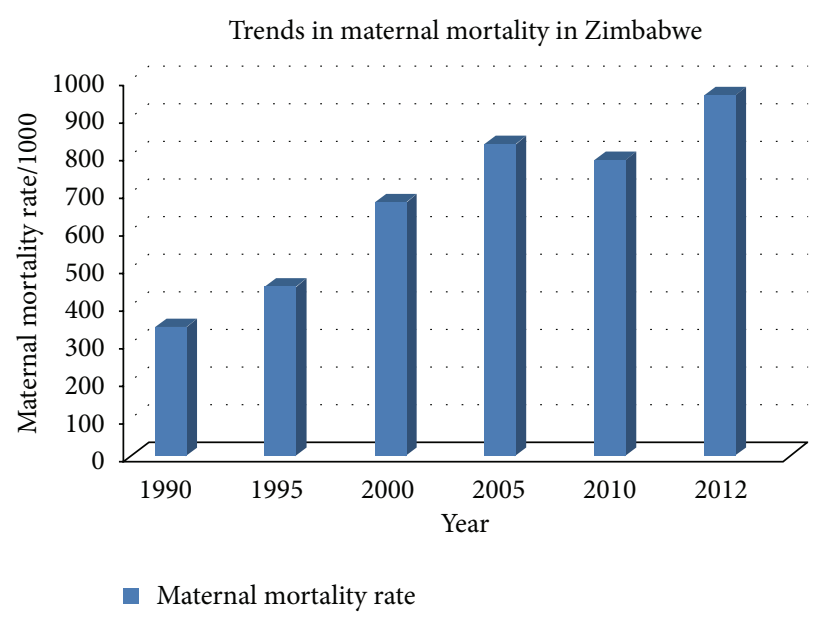

Figure 3: Source: Mlambo et al. 2013 [47].

the time lost in recognizing the seriousness of the situation and deciding whether or not to seek medical attention; the time needed for reaching a health facility or a trained service provider, once a decision was taken to seek care; and delay in receiving expeditious and effective care, once the challenge of referral was overcome. In 2009 the Ministry of Health and Child Welfare of Zimbabwe highlighted that there was an increase in the underutilization of the health care system especially the public health sector which is the major supplier of health care [34]. Chimhete [31] reported that many people were being forced to seek traditional care due to high staff turnover, high hospital costs, and shortages of essential drugs at most clinics and hospitals. This shows that a new pattern of health-seeking behaviour has emerged where people are opting for traditional and other care rather than medical care.

Appropriate care during prenatal pregnancy, delivery, and postnatal care are important for the health of both the mother and the baby. The introduction of conventional medicine in sub-Saharan African countries saw a gradual distribution of health facilities in both urban and rural settings. The aim was to improve overall healthcare and regarding maternal health the target was to reduce maternal and infants' mortality as well as morbidity of the mothers that followed after births. Childbearing women were advised and encouraged to attend antenatal care and deliver at health facilities with the help of skilled personnel [35, 36]. This advocacy was done in both rural and urban areas However, coverage of antenatal care is slightly higher in urban areas than in rural areas. Poor infrastructure, roads reach of health facility, and unavailability of trained personnel especially in government institutions are cited as contributing factors. Ministry of Health and Child Welfare (MoHCW) reported a $60 \%$ of physicians' vacant posts across the country [37]. Skilled attendance at delivery declined from $73 \%$ in 1999 to $69 \%$ in 2006 (ZDHS), and then fell to 60\% in 2009 (MIMS). Institutional deliveries also declined from $72 \%$ in 1999 to $68 \%$ in 2006 [25] and in 2009 MIMS reported a 7\% decline to $61 \%$. According to WHO [38] Zimbabwe's MMR is 790 deaths per 100,000 live births and only $60-69 \%$ of births are attended by 
trained health professionals depending on the geographical location. Women in Zimbabwe thus suffer a high risk of dying during pregnancy, childbirth, and the puerperium. Maternal and perinatal mortality constitute a significant burden of disease in Zimbabwe [24].

The government policy stance towards TBAs has undergone transformations as influenced by the policy dispensations of the day. In the first two decades following Zimbabwe's independence TBAs were officially recognised by the government [39]. The training of TBAs was thus considered an important strategy for improving infant and maternal health care with the primary aim of making home deliveries cleaner and safer [40]. Efforts were also directed at facilitating integration of the two health systems (traditional and biomedical), which, according to Jordan [3], is essential for preserving the best elements of each for the benefit of the mothers and children. In Zimbabwe, TBAs were also trained to recognize and to refer high-risk women and those likely to have complications to the hospital. Continuous supervision and monitoring of the TBAs were done through home visits, meetings at the clinics, and quarterly reports produced by TBAs on what they have been doing [40]. It is estimated that about 15,000 TBAs have been trained in the entire country since the programme was launched in 1983 [40]. However, TBA training has been criticized for being complicated and inappropriate for elderly and at times illiterate women, due to its reliance on Western, urban models of training and for using culturally inappropriate teaching methods $[5,10$, 41]. Others have argued that the training entails merely biomedical knowledge and practice. For example, Houston [42] highlights that the training programme failed to take account of the cultural aspects of the TBA knowledge and practices, to create good working relations, or to learn how TBAs operate as a basis for developing training material. This can partly explain their continued existence parallel to the formal health care system. The emphasis on biomedicine in the training of TBAs is being challenged, and understanding the local knowledge and practices is considered central for incorporating the TBAs into evidence-based care $[9,42,43]$.

Immediate post-independent Zimbabwe did not charge user fees for health services in public facilities. The socialist informed government policies focused universal access to health with slogans like "health for all" being catch-political phrases of post independent Zimbabwe. User fees were introduced and then increased during the 1990s as part of the Zimbabwe Economic Structural Adjustment Program (ESAP). Although designed to improve service quality to ensure access to heath for poor people and vulnerable groups, the application of user fees did not result in improved quality of care and in fact has had a negative impact on equitable access in Zimbabwe. The Poverty Assessment Study Survey [18] showed that a lack of available money was the main reason for patients not seeking treatment for illness/injuries. Chirwa et al. [44] highlight that the implementation of the user fees policy has been erratic and administratively complicated and has lead to compromised equity in service resulting in a 30 percent decline in use of rural health centres.

The comprehensive user fee policy for public health facilities was introduced in January 2002. This policy includes: No fees to be charged at Government RCH and RDC clinics, no fees to be charged for maternity services, free health services for children under 5, free TB treatment-public and private sector, and free treatment for pensioners. Though provisions in the user fee policy include free access for children under 5 , pregnant women, and the elderly, the policy is also widely misunderstood, and establishing eligibility for exemption of fees on the basis of poverty has been difficult. Efforts to affect the exemptions are also complicated by the limited ability to monitor and enforce the legal implementation of the policy and by the different ministerial portfolios covering health. Despite the exemptions, pressures from the economic crisis have reduced resources to frontline services. The provisions for pregnant women, children under 5 , and the elderly are not always being realised in practice. The Vital Medicines and Health Services Surveys suggest that only about 53 percent of health facilities provide a full maternity service free of charge. Other facilities charge fees with prices varying from US $\$ 3$ to US $\$ 50$, with higher prices in urban locations [45]. User fees are also charged on an ad hoc basis for emergency services such as C-sections, for blood transfusion, and postacute care (PAC). Generally, user fees present a barrier to health care and contribute to greater disparities in access, effectively excluding poorer people from the formal health care system. The Maternal and Perinatal Mortality Study [46] cited user fees as the main reason for lack of access to ante, postnatal, and institutional delivery services.

Data suggests that demand for health services is higher in those facilities that do not charge fees. For the majority of Zimbabweans, physical (such as distance, transport, and restricted opening hours) and sociocultural barriers exist and are more pronounced for people in rural areas, the poor, and those belonging to particular religious communities. Joint analysis conducted by Equinet and the Collaborating Centre for Operational Research (CCORE) in 2010 shows that disparities in maternal health have increased in the past decade and health services, other sociocultural barriers exist for some religious communities, such as the Apostolic communities, which represent an increasing proportion of the total population. These groups exhibit poorer acceptance and coverage of health interventions. Maternal health care has thus deteriorated more for the poorest women than for women of higher socioeconomic status. This trend is depicted in the differences in coverage of skilled birth attendance.

Delivery care in facilities (even in the absence of complications) was not seen as affordable by users or staff. This is likely to be one factor behind the high rate of home deliveries. Chirwa et al. [44] observed that users are being charged for primary care in rural areas, not least because under the policy of decentralisation the majority of clinics are managed by local authorities, which are able to set their own charging policies. Rural and urban clinics collect fees but do not retain them. They were reported to receive very little back by way of financial support from district councils and municipalities. They therefore suffer a double disadvantage of higher barriers for users and a lack of funds to reinvest in services. Upfront payments are taken for consultation. The MoHCW policy of free care at clinic level has not been applied uniformly by local government and mission clinics. The rural clinics used 
to be free but between 2009 and 2010 they started to charge. Municipal clinics charge more and always have done so.

\section{The Practice of TBAs}

Mathole et al. [27] present the complex world of TBAs in Zimbabwe. They propound that TBA world is predominantly a female preserve and that men could not be TBAs due to the unknown, unpredictable, and possibly disrespectful behavior likely to be exhibited following beer drinking. Most often TBAs acquire midwifery skills through assisting other TBAs for years before being able to practice independently. TBAs are a diverse group and according to Mathole et al.s [27] observations they can be classified into three categories. The first is comprised of TBAs who are ordinary women who acquired their skills through learning from others and may only provide antenatal care. They may have knowledge of special herbs known to be important for cervical dilation, believed to be necessary in precipitating labour during delivery. The second category is comprised of TBAs who are traditional healers/diviners. These are believed to have supernatural powers to protect pregnant women against witchcraft. These TBAs can also recommend herbs known to be effective in stabilising early pregnancy. The third group is comprised of TBAs known as prophets and this group is associated with the church. They use faith healing through prayer and holy water. Interesting to note is that there appear to be competition and mistrust among the diverse categories of TBAs and that women combine various options of care.

Historically, indigenous practices constituted the major source of survival in Africa, and at the centre of these practices was the care of pregnant women. Despite the condemnation of traditional health practices and the introduction and sustained promotion of modern Western medicine, traditional medicine is not fading away in Africa [48]. Poverty and the inaccessibility of health facilities, among others, lead many Africans to depend on traditional health practitioners for medical care. In Zimbabwe the field of maternal health care has since time immemorial been entrusted to TBAs. TBAs are part of the Zimbabwe Traditional Healers Association (ZINATHA). TBAs' midwifery roles include taking care of pregnancy and childbirth, treating infertility, and playing an advisory role in family matters [22, 49]. Traditionally, the role of TBAs on reproductive health starts immediately after a woman conceives pregnancy. They are consulted for any health problems occurring among pregnant women until after delivery and have rich knowledge of traditional medicine used for managing pregnancy and child delivery. Additionally, TBAs educate pregnant women on appropriate diet to take, pregnancy-related taboos, and on how to take care of infants after birth and are known to have some knowledge of risk signs during pregnancy. Moreover, TBAs are also responsible for management of family planning, getting opposite sex for a woman who was giving births of one sex, managing some temporally impotence, and infertility using traditional remedies. Some TBAs are also involved in girls initiation to adulthood in some ethnic groups [50-52]. Above all TBAs are primarily involved in child deliveries.
The significance of TBAs has been denied by professional western trained health practitioners and other scientists until during the late 1980s. The World Health Organization through Safe Motherhood Program of 1987 found TBAs to have a significant role in reducing maternal and newborn mortality. It was ascertained that trained TBAs in sub-Sahara Africa can have positive impact on reducing maternal and newborn mortality if the Safe Motherhood programme is well implemented with systematic followup after training. Collaboration between trained hospital workers and TBAs can prove to be fruitful especially in country like Zimbabwe with a health system on its knees. For example, TBAs can help to break socio-cultural barriers on intervention on reproductive health programmes as they are insider to the communities they serve. However, projects targeting TBAs ought to be familiarized with the target group, build trust, transparency, and tolerance, are willing to learn, and create a better relationship with them rather than a top-down approach. Evidence exists that trained TBAs can be fully utilized in reducing maternal and new-born mortality rate in rural areas if their activities are effectively collaborated. However, it is important to note that child delivery is a socio-cultural event, and thus in order to bring effective intervention TBAs who have been involved in child deliveries for years ought to be taken on board on reproductive health interventions. They are therefore key actors in reducing maternal and infants mortality as well as morbidity of the mothers.

The government of Zimbabwe has come up with policies such as the National Health Policy and the Reproductive Health Policy of 2003 and programs like the Zimbabwe Expanded Programme on Immunization (ZEPI), Breastfeeding Campaign Programs, and the Zimbabwe Maternal and Neonatal Health Road Map which are built upon the various agreements and objectives of the international conferences and summits aimed at reducing mortality [24]. The Zimbabwe Maternal and Neonatal Health Road Map, for example, is a national framework for planned activities aimed at significantly improving maternal and newborn health services at institutional and programme levels [24]. The framework's objectives are to provide skilled attendance during pregnancy, child birth, and postnatal period at all levels of the health care delivery system and to strengthen the capacity of individuals, families, communities, civil society, and the government to improve maternal and newborn health [24]. Evidently, these policies push to the fringes and further marginalize TBAs and the services they offer to society. However, the objectives of these frameworks are difficult if not impossible to achieve without recourse to TBAs in the context of Zimbabwe given the frail and suffocating nature of the health care delivery system. International debates have ensued on suitable approaches to reduce maternal mortality in poor countries arguing for the use of the TBAs [53-55]. Lack of consensus regarding failure of TBAs to affect positive maternal outcomes resulted in a policy shift to skilled birth attendance that was suggested [1].

Papen [56] argues that pregnancy represents a highly constructed social world that has been designed for women to adhere to. Indigenous beliefs and practices are informed 
by the cultural traits passed from one generation to the next. These practices are innate and deeply rooted and embedded in these societies and thus define the people's life world and are thus difficult to change as people have adhered to them throughout their entire lives. Belief systems play a major role in the health-care-seeking behavior of individuals [57]. Despite their obvious significance and the need to incorporate them in maternal care improving strategies, the cultural aspects of pregnancy are often neglected as are their custodians, the TBAs. Reasons for most TBA assisted home deliveries include poverty, distance to health facilities, lack of information, inadequate services and medical supplies, lack of competent personnel in reproductive health at the health facilities, and above all the cultural practices related to birthing $[14,58]$. All these factors are likely to contribute to women preferences to go to TBAs for child delivery than to formal health facilities.

The role of traditional birth attendants in provision of health care in resource-poor countries is still important because of the current inadequacy of human resource for health. TBAs are and will remain the main providers of child deliveries in most rural areas for years to come. The reduction of maternal and new-born mortality in such contexts requires rigorous efforts by governments and nongovernmental organizations in identifying renowned TBAs and recruiting and training them. As argued earlier TBAs are experts on their own right and thus they deserve respect in aspect of reproductive health issues to women. Creation of dialogue, trustworthiness, patience, tolerance, willingness to collaborate, transparency and familiarity during training are keys when working with TBAs as partners in health care and sharing experiences. TBAs are product of cultural system in community, and one of their roles is to protect culture from being invaded by other cultures $[51,52]$.

\section{Conclusion}

Experts on reproductive health have painted a grim picture of maternal and child health in sub-Saharan Africa. In 2005, WHO estimated that if nothing was done by 2015 there would be 2.5 million maternal deaths, 2.5 million child deaths, and 49 million maternal disabilities in the subSaharan region [58]. The increasing maternal and relatively high infant mortality rates in Africa call for collective efforts that should take cultural value on reproductive health and child delivery components on board in order to meet the 4th and 5th Millennium Development Goals. Despite the significant role played by TBAs in assisting child deliveries and their rootedness in their societies' cultural beliefs and values, they have been neglected since the introduction of conventional medicine in sub-Saharan and other developing countries [58, 59]. Governments of Zimbabwe need to reconsider paying attention to TBAs as an integral resource for all programmes introduced in response to the increasing maternal and new-born mortality rates. Many lives could be saved using relatively easy and cheap methods partly by training TBAs who take on board the sociocultural practices related to child birth and caring for the infants and are always omnipresent in villages $[14,58]$. Efforts are being made by governments in developing countries to reduce maternal deaths, stillbirths, and neonatal deaths related to intrapartum events in unattended births which include use of antinatal clinic, immunization, and insistence to deliver in health facilities $[13,14,18]$. If TBAs could be taken on board they could avert some of the health problems related to maternal and new-born mortality. In Zimbabwe, the calls for institutional birthing and/or skilled attendance at birth remain a colorful dream for the majority of rural women. This calls for government to effect policies that speak to the lived realities of these rural often poor and/or marginalized women. The current disregard for TBAs and the services they render to society is inconceivable given the realities obtained on the ground. Moreover, there is limited application of gender analysis in formulation of policies and strategies at all levels and involvement and participation of women in decision making are limited, mainly due to existing sociocultural attitudes, beliefs, practices, and norms. However, because pregnancy is the domain of women there is need to take into cognizance the gender concerns.

In Zimbabwe, high maternal mortality is due to lack of skilled manpower, poor transport and communication systems, poor acceptance of formal health care services, inadequate equipment and drugs, and poverty in general. This is compounded by declining skilled attendance at delivery. Many of the rural health facilities are manned by auxiliary nurses and/or skeleton staff who are ill-trained on provision of health services. Thus, the only way at present to arrest the current situation of maternal health involves taking on board the TBAs who are available in the villages and are within reach. These TBAs should be trained on safe delivery methods emphasizing dialogue, trustworthiness, respect, transparency, willingness to learn, and sharing of knowledge in the learning process. Cultural factors present a significant barrier in reducing maternal and new-born mortality rates in the community and these can be easily solved by working collaboratively with TBAs. A lack of understanding of cultural beliefs and practices results in a lack of support for the health system, thus contributing to delayed attendance of antenatal clinics as well as homebirthing.

Additionally, the ambivalence in terms of policy on the part of the government regarding traditional medical practices and specifically TBAs practice leaves TBAs in a predicament. On one hand, sociocultural values as well as tradition imbue them power and authority to manage pregnancies and assist in child deliveries. On the other hand, government policies expounded through the Ministry of Health $(\mathrm{MoH})$ programs and policies appear to be relegating them to the fringes of healthcare provision. However, in a country with a failing health system characterized by mass exodus of qualified personnel, availability of drugs and understaffing of healthcare centres, among others, TBAs remain the lifeline for many women in the country.

\section{Conflict of Interests}

The authors declare that there is no conflict of interests regarding the publication of this paper. 


\section{References}

[1] WHO, Making Pregnancy Safer: The Critical Role of the Skilled Attendant: A Joint Statement by WHO, ICM and FIGO, WHO, Geneva, Switzerland, 2004.

[2] S. Kruske and L. Barclay, "Effect of shifting policies on traditional birth attendant training," Journal of Midwifery and Women's Health, vol. 49, no. 4, pp. 306-311, 2004.

[3] B. Jordan, "High technology: the case of obstetrics," World Health Forum, vol. 8, pp. 312-319, 1987.

[4] S. Graham, Traditional Birth Attendants in Karamoja [Ph.D. thesis], South Bank University, Uganda, 1999.

[5] N. Goldman and D. A. Glei, "Evaluation of midwifery care: results from a survey in rural Guatemala," Social Science and Medicine, vol. 56, no. 4, pp. 685-700, 2003.

[6] A. Bij de Vaate, R. Coleman, H. Manneh, and G. Walraven, "Knowledge, attitudes and practices of trained traditional birth attendants in the Gambia in the prevention, recognition and management of postpartum haemorrhage," Midwifery, vol. 18, no. 1, pp. 3-11, 2002.

[7] World Health Organization, Reduction of Maternal Mortality: A Joint WHO/UNFPA/UNCEF/World Bank Statement, World Health Organization, Geneva, Switzerland, 1999.

[8] A. O. Imogie, E. O. Agwubike, and K. Aluko, "Assessing the role of traditional birth attendants (TBAs) in health care delivery in Edo State, Nigeria," African Journal of Reproductive Health, vol. 6, no. 2, pp. 94-100, 2002.

[9] J. B. Smith, N. A. Coleman, J. A. Fortney, J. De-Graft Johnson, D. W. Blumhagen, and T. W. Grey, "The impact of traditional birth attendant training on delivery complications in Ghana," Health Policy and Planning, vol. 15, no. 3, pp. 326-331, 2000.

[10] B. T. Sparks, "A descriptive study of the changing roles and practices of traditional birth attendants in Zimbabwe," Journal of Nurse-Midwifery, vol. 35, no. 3, pp. 150-161, 1990.

[11] J. Mutambirwa, "Health problems in rural communities, Zimbabwe," Social Science and Medicine, vol. 29, no. 8, pp. 927-932, 1989.

[12] S. Crowe, M. Utley, A. Costello, and C. Pagel, "How many births in sub-Saharan Africa and South Asia will not be attended by a skilled birth attendant between 2011 and 2015?” BMC Pregnancy and Childbirth, vol. 12, article 4, 2012.

[13] Jamison, D. T. S. A. Shahid-Salles, J. Jamison, J. E. Lawn, and J. Zupan, "Incorporating deaths near time of birth into estimates of the global burden of disease," in Global Burden of Disease and Risk Factors, A. D. In Lopez, C. D. Mathers, M. Ezzati, D. T. Jamison, and C. J. L. Murray, Eds., pp. 427-462, Oxford University Press, New York, NY, USA, 2006.

[14] WHO, "Maternal mortality," Fact Sheet 348, World Health Organization, Geneva, Switzerland, 2012.

[15] Zimbabwe National Statistics Agency (ZIMSTAT) and ICF International, "Zimbabwe Demographic and Health Survey 2010-2011, Preliminary Report”.

[16] World Health Organization, International Statistical Classification of Diseases and Related Health Problems, WHO, Geneva, Switzerland, 10th edition, 1992.

[17] TARSC and MoHCW, Equity Watch: assessing progress towards equity in health in Zimbabwe, EQUINET Harare, 2011.

[18] Ministry of Public Service Labour and Social Welfare, "2003 poverty assessment study survey," Draft Main Report, 2006.

[19] Goz (Government of Zimbabwe), "The National Health Strategy for Zimbabwe (2009-2013), Equity and Quality in Health: A People's Right," 2010.
[20] D. Auret, A Decade of Development Zimbabwe 1980-1990, Mambo Press, Gweru, Zimbabwe, 1990.

[21] D. Makuto and V. James, "Study on Access to Health Care Services in Zimbabwe," ECORYS Nederland BV, European Union, 2007.

[22] G. Hansson, Mwanandimai: Toward an Understanding of Preparation for Motherhood and Childcare in the Transitional Mberengwa District, Uppsala University, Uppsala, Zimbabwe, 1996.

[23] P. Nhindiri, S. Munjanja, I. Zhanda, G. Lindmarka, and L. Nystrom, "A community based study on utilization of maternity services in rural Zimbabwe," African Health Sciences, vol. 3, no. 4, pp. 120-125.

[24] WHO/UNICEF/UNFPA and The World Bank, Maternal Mortality in 2005. Estimates Developed By WHO, UNICEF, UNFPA and the World Bank, World Health Organisation, Geneva, Switzerland, 2007.

[25] CSO and Macro, Zimbabwe Demographic and Health Survey 2005-2006, CSO and Macro International, Calverton, Md, USA, 2007.

[26] V. D. Tsu, "Antenatal screening: its use in assessing obstetric risk factors in Zimbabwe," Journal of Epidemiology and Community Health, vol. 48, no. 3, pp. 297-305, 1994.

[27] T. Mathole, G. Lindmark, F. Majoko, and B. M. Ahlberg, "A qualitative study of women's perspectives of antenatal care in a rural area of Zimbabwe," Midwifery, vol. 20, no. 2, pp. 122-132, 2004.

[28] Central Statistical Office (Zimbabwe) and Macro International, Zimbabwe Demographic and Health Survey 1999, Central Statistical Office and Macro International, Calverton, Md, USA, 2000.

[29] World Health Organization, "Making pregnancy safer: why is this issue important?" Fact Sheet 276, World Health Organization, Geneva, Switzerland, 2004.

[30] Central Statistical Office (CSO) (Zimbabwe) and UNICEF, "Multiple indicators monitoring survey (MIMS) 2009," Preliminary Report, 2009.

[31] C. Chimhete, "High Fees Drive Patients Away From Hospitals. The Sunday Mirror," pp. 1-3, Harare, Zimbabwe, 2003.

[32] R. Mukumbura, "Zimbabwe: more people turn to traditional medicine," Africanews, vol. 54, pp. 1-3, 2000.

[33] J. Ncube, "With doctors and drugs in short supply, Zimbabwe's Traditional Healers are coming to the rescue," 2003, Orbit, 66.

[34] MoHCW, The National Health Strategy For Zimbabwe (20092013), Equity and Quality in Health: A People's Right, MOHCW, 2009.

[35] C. M. Good, "Pioneer Medical Missions in Colonial Africa," Social Science and Medicine, vol. 32, pp. 1-10, 1991.

[36] S. Iliffe, "Hospital at home: from red to amber," British Medical Journal, vol. 316, pp. 1761-1762, 1998.

[37] ZHWO (Zimbabwe Health Workforce Observatory), Human Resources for Health Country Profile, World Health Organization, 2009.

[38] WHO, Global Observatory, World Health Organisation, 2011.

[39] Wintergren, "Traditional midwifery gathering," A World First Event Common Knowledge Newsletter, vol. 3, pp. 1-9, 1998.

[40] Ministry of Health and Child Welfare, Traditional Midwives Training Guidelines, Government of Zimbabwe, Harare, Zimbabwe, 1997. 
[41] C. Stephens, "Training urban traditional birth attendants: balancing international policy and local reality. Preliminary evidence from the slums of India on the attitudes and practice of clients and practitioners," Social Science and Medicine, vol. 35, no. 6, pp. 811-817, 1992.

[42] J. Houston, "Weaving a Cultural Exchange: Midwives Working Together. Childbirth Solutions," pp. 1-5, 2000.

[43] R. Davis-Floyd, "Anthropological Perspectives on Global Issues in Midwifery," Midwifery Today, pp. 1-12, 2002.

[44] Y. Chirwa, S. Witter, M. Munjoma et al., "The Human Resource Implication of Improving Financial Risk Protection for Mothers and Newborns in Zimbabwe BMC Health Services Research," pp. 13-197, 2013.

[45] Zimbabwe's Association of Doctors for Human Rights Annual Report, 2009, http://www.zadhr.org/.

[46] S. P. Munjanja, L. Nystrom, M. Nyandoro, and T. Magwali, "Maternal and Perinatal Mortality Study," 2007, http://www .unicef.org/zimbabwe/ZMPMS_report.pdf.

[47] C. Mlambo, C. Chinamo, and T. Zingwe, "An investigation into the causes of maternal mortality in Zimbabwe," Mediterranean Journal of Social Sciences, vol. 4, no. 14, 2013.

[48] F. M. Mulaudzi, "Synergy between indigenous knowledge, modern health care and scientific research: a challenge in The 21st century," Health SA Gesondheid, vol. 16, pp. 14-20, 2001.

[49] G. L. Chavunduka, Traditional Medicine in Modern Zimbabwe, University of Zimbabwe Publications, Harare, Zimbabwe, 1994.

[50] L. M. Swantz, Religious and magical rites of bantu women in Tanzania [M. Phil. Thesis], University of Dar-Es-Salaam, Dar es Salaam, Tanzania, 1966.

[51] S. Cosminsky, "Traditional midwifery and contraception," in Traditional Medicine and Health Care Coverage, R. H. Bannerman, J. Burton, and C. Wen-Chieh, Eds., World Health Organization, Geneva, Switzerland, 1983.

[52] E. J. Kayombo, "Traditional birth attendants (tbas) and maternal health care in Tanzania," in Issues and Perspectives on Health Care in Contemporary Sub-Saharan Africa by Studies in Africa Health and Medicine, E. Kalipen and P. Thiuri, Eds., vol. 8, pp. 288-305, The Edwin Mellen Oress Lewston, Queenston, Lampeter, UK, 1997.

[53] P. J. Putney and B. Smith, "The training and practice of traditional birth attendants in guatemala," Report Prepared for Technologies for Primary Health Care USAID, 1989.

[54] S. Cosminsky, "Childbirth and midwifery on a Guatemalan finca," Medical Anthropology, vol. 1, no. 3, pp. 69-104, 1977.

[55] J. B. Lang and E. D. Elkin, "A study of the beliefs and birthing practices of traditional midwives in rural guatemala," Journal of Nurse-Midwifery, vol. 42, no. 1, pp. 25-31, 1997.

[56] U. Papen, "Pregnancy starts with a literacy event: pregnancy and antenatal care as textually mediated experiences," Ethnography, vol. 9, no. 3, pp. 377-402, 2008.

[57] B. T. Shaikh and J. Hatcher, "Health seeking behaviour and health service utilization in Pakistan: challenging the policy makers," Journal of Public Health, vol. 27, no. 1, pp. 49-54, 2005.

[58] M. Grieco and J. Turner, "Maternal Mortality: Africa's Burden, Tookit on Gender, Transport and Maternal Mortality, 2005.

[59] K. Busia and O. M. J. Kasilo, "Collaboration between traditional Health practitioners a and conventional health practitioners: some country experiences," The African Health Monitor, vol. 13, 2010. 

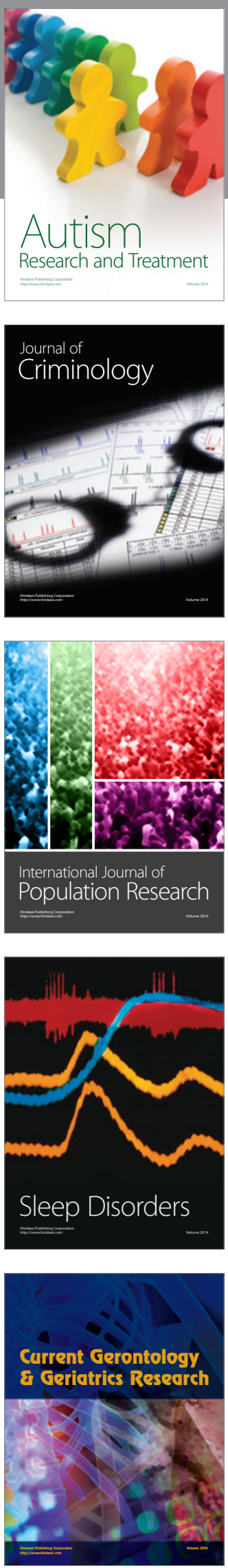
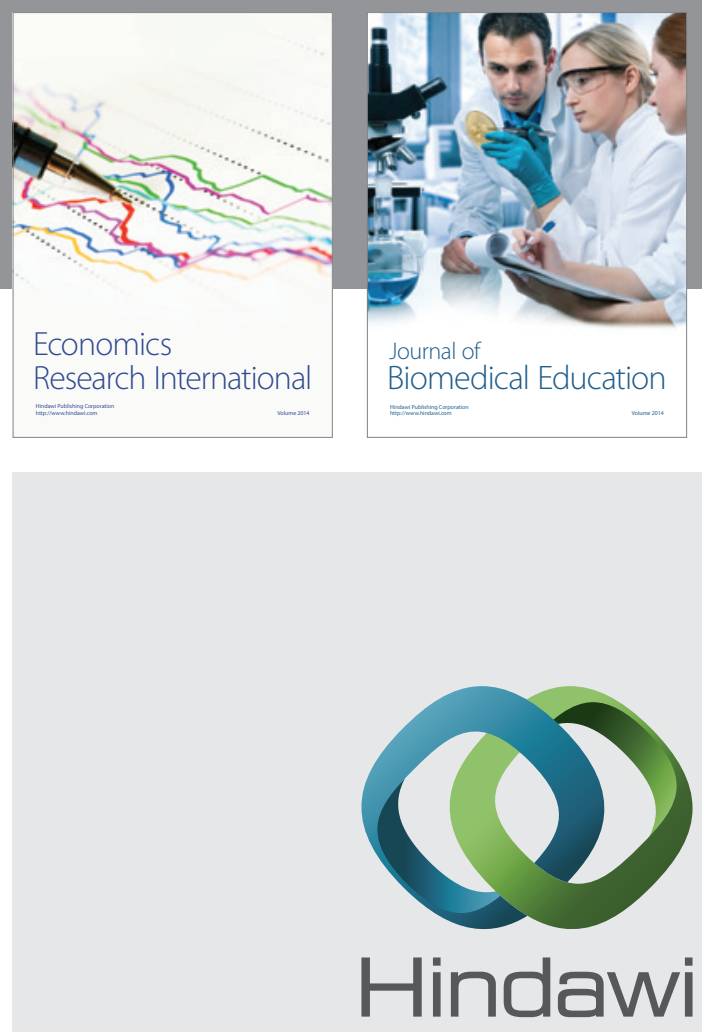

Submit your manuscripts at

http://www.hindawi.com
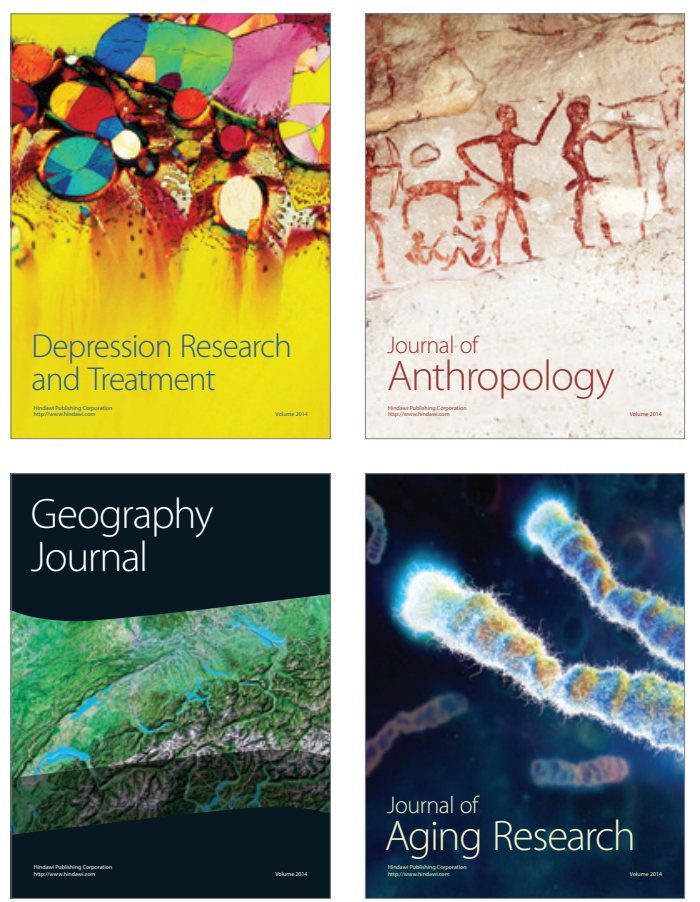
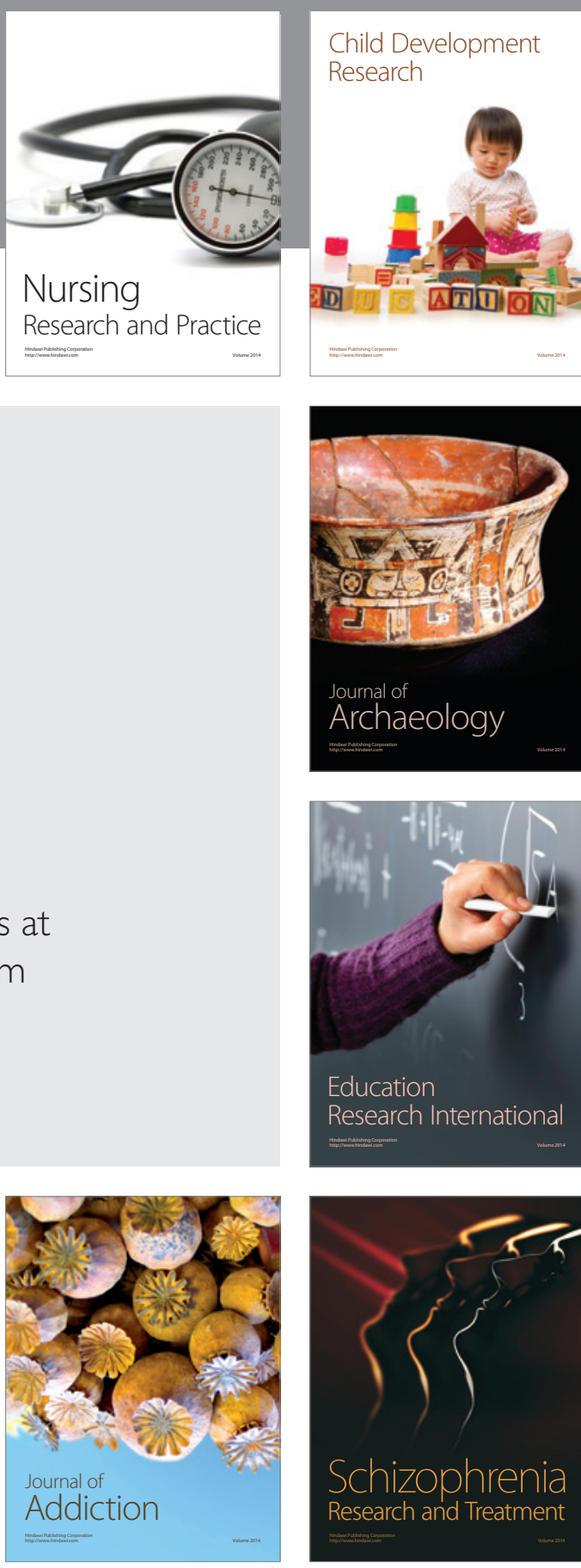

(D)
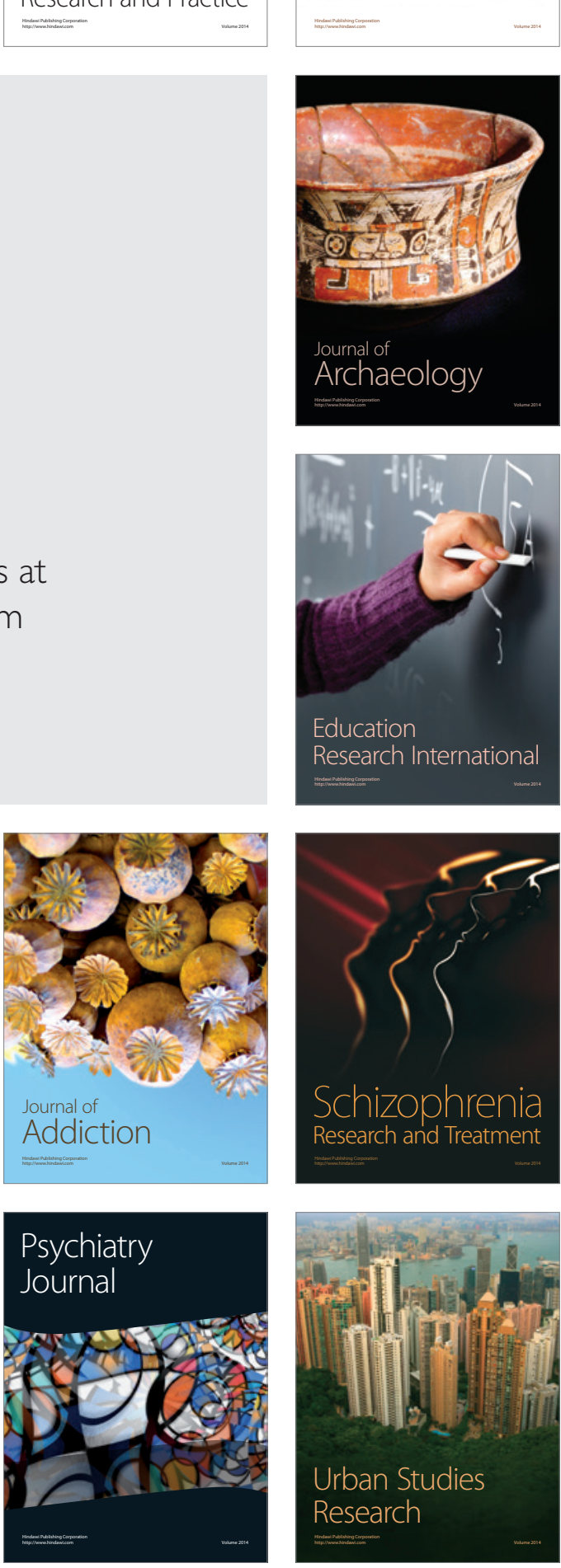